\title{
Proposição de um índice de QUALIDADE de estações de TRATAMENTO DE ÁGUA (IQETA)
}

\author{
Proposal of A QUALITY INDEX APPLIED ON THE WATER \\ TREATMENT PLANTS
}

\begin{abstract}
VANESSA CRISTINA LOPES
Engenheira Civil (Unicamp) e aluna do Programa de Pós-Graduação em Saneamento, Meio Ambiente e

Recursos Hídricos da UFMG

MARCELO LIBÂNIO

Engenheiro Civil e Mestre em Engenharia Sanitária (UFMG), Doutor em Hidráulica e Saneamento (USP) e

Professor Adjunto do Departamento de Engenharia Hidráulica e Recursos Hídricos da UFMG
\end{abstract}

Recebido: 19/01/05 Aceito: 28/09/05

\section{RESUMO}

O presente trabalho objetiva a proposição de um Índice de Qualidade de Estação de Tratamento de Água (IQETA), aplicável a estaçôes de tecnologia convencional, que permita comparar o desempenho das estaçôes por meio de uma metodologia que transcenda o simples atendimento ao padrão de potabilidade. A metodologia para a elaboração do IQETA fundamentou-se basicamente na mesma utilizada para o desenvolvimento do IQA. A posterior aplicação do IQETA a dez estações de portes distintos validou-o como ferramenta de avaliação. Verificou-se clara tendência das estaçôes com melhor desempenho - produzindo água filtrada de melhor qualidade, em termos de turbidez - serem contempladas com maiores valores para o IQETA, demonstrando a utilidade do índice como uma ferramenta capaz de auxiliar na administração de sistemas de produção de água para consumo humano.

PALAVRAS-CHAVE: Índice de qualidade, avaliação de estaçôes, tratamento de água.

\section{INTROPUÇÃO E RELEVÂNČIA}

Os fatores intervenientes no desempenho das estaçôes de tratamento de água referem-se, basicamente, à adequação das características da água bruta à tecnologia de tratamento, à relação vazão afluente/capacidade da estação e à qualidade da operação. Para a avaliação da eficiência global da estação, a tais fatores somam-se ainda as características do efluente e o custo do tratamento, intrinsecamente vinculado à dosagem e tipo de coagulantes, à duração das carreiras de filtração, à existência de curtos-circuitos entre as unidades, entre outros. A multiplicidade destes fatores tem dificultado a necessária hierarquização entre as unidades - como ocorre com os cursos

\begin{abstract}
This work aims the proposal of a Water Treatment Plant Quality Index (WTPQI), applied on the conventional plants, to compare the performance of plants by means a methodology beyond compliance of the drinking water guideline. The WTPQI methodology was based on the same utilized for the Water Quality Index. The WTPQI application on ten plants has validated it as a good tool for evaluation plants. A clear tendency of plants with good performance, in terms of turbidity effluent, keeping high WTPQI values was verified. This fact demonstrated the usefulness of the index as a tool able to help water supply systems management.
\end{abstract}

KEYWORDS: Quality index, water treatment plant evaluation, water treatment.

d'água - que certamente nortearia a atuação dos responsáveis pela administração dos sistemas de abastecimento, quer na operação quer na ampliação das unidades potabilizadoras. Como conseqüência, a avaliação do desempenho das estações de tratamento de água tem sido freqüentemente analisada no meio técnico de forma reducionista, restringindo-se quase que tão somente - ao atendimento ao padrão de potabilidade.

A avaliação do desempenho global das estações de tratamento de água, e conseqüentemente da qualidade da operação, suscita algumas questões:

i) Para estaçóes empregando a mesma tecnologia de tratamento e adequando a água bruta ao padrão de potabilidade vigente, de que forma deve ser avaliada sua eficiência ou, nesta mesma vertente, cotejados os custos inerentes à potabilização, caso a água bruta apresente distintas características?

ii) $\mathrm{O}$ índice de sobrecarga - materializado em parâmetros hidráulicos, tais como tempo de floculação, velocidade de sedimentação e taxa de filtração - é ou não mais relevante em relação ao nível técnico da operação no que tange à qualidade da água produzida?

iii) Estações, com a mesma tecnologia de tratamento, potabilizando e fornecendo águas de características semelhantes, podem ser comparadas quando apresentam distintos custos do tratamento?

iv) $\mathrm{Na}$ perspectiva de ampliação das unidades de tratamento, quais etapas devem ser priorizadas?

v) Há distinção marcante na qualidade da operação entre unidades de tra- 
tamento operadas pela mesma concessionária (companhias estaduais de saneamento) localizadas em regiōes socioeconomicamente semelhantes?

A estas e outras questóes poder-se-ia inserir também a avaliação do impacto ambiental nos cursos d'água acarretado pelo lançamento do lodo gerado nas unidades de decantação, por ocasião das descargas de fundo, e/ou das águas de lavagem dos filtros. Desta forma, há necessidade de um modelo matemático que permita aos órgãos gestores dos sistemas de abastecimento, em especial as companhias estaduais de saneamento, efetuar uma análise mais acurada das diversas instalaçôes potabilizadoras, para melhor alocar as verbas de ampliação e os recursos humanos disponíveis.

A perspectiva de desenvolvimento de uma metodologia de avaliação de estaçôes de tratamento de água não é nova. Renner et al (1993) apresentam uma discussão acerca dos resultados da implantação de um programa de otimização do processo de tratamento, denominado CPE (Comprehensive Evaluation Program), em 36 estações localizadas nos Estados Unidos. Este identificou limitação de desempenho devido a problemas operacionais em 29 delas e a possibilidade de otimizar o tratamento destas estaçôes sem maiores investimentos.

A opção por um Índice de Qualidade como ferramenta a ser desenvolvida justifica-se pela utilização de dados facilmente obteníveis na operação rotineira da estação e por permitir a compreensão pelo público leigo, pois em algumas situações os responsáveis pela alocação de recursos não detêm conhecimento dos processos e operações envolvidos na potabilização. Sendo inteligível ao público leigo o IQETA poderá também ser utilizado para a conscientização da importância do desempenho adequado da unidade e para a minimização da exposição potencial da população a organismos patogênicos por meio da água potável.

\section{OBJETIVO}

Diante do exposto, o trabalho propóe o estabelecimento de um índice de avaliação de estaçóes de tratamento de água (IQETA) como ferramenta que permita às administrações de sistemas de abastecimento comparar o desempenho das estaçōes. Adicionalmente o trabalho propõe: (i) Levantar os parâmetros intervenientes na performance de cada processo ou operação envolvidos no tra- tamento convencional; (ii) hierarquizar os parâmetros intervenientes para o bom desempenho das estações de tratamento de água; (iii) validar o IQETA a partir dos dados de operação de dez estações de tratamento de água de portes distintos.

\section{Revisão da Literatura}

\section{Avaliação e otimização de estações de tratamento de água}

O tratamento de água para consumo humano como um dos pilares do saneamento básico vivencia já há alguns anos nítida dicotomia. Por um lado sucedem-se padrōes de potabilidade progressivamente mais restritivos - em termos do crescente número de parâmetros e dos limites aos mesmos relacionados -, por outro a deterioração das características das águas naturais por poluição pontual e difusa decorrente, sobretudo, das atividades antrópicas.

Limites mais restritivos à turbidez da água filtrada fundamentaram-se, em um primeiro momento, na maior eficiência da cloração na inativação de microrganismos e, em um segundo, na perspectiva de fomentar a remoção de cistos e oocistos de protozoários. Nesta última vertente, diversos trabalhos sinalizam para maior remoção de tais patogênicos associada à produção de água potável com turbidez inferior a $0,1 \mathrm{uT}$. Como exemplo pode ser citada a pesquisa realizada utilizando-se filtros em escala-piloto e real, como filtração direta e tratamento convencional, monitorados durante dois anos. Demonstrou-se remoção mais consistente de Giardia e Crypto alcançada com produção de água com baixa turbidez (0,1 a 0,2 uT), embora com coeficiente de determinação não elevado $\left(r^{2}=0,64\right)$. Quando o desempenho da estação variava com as flutuações de turbidez da água bruta, uma alta variabilidade na concentração de cistos era observada no efluente coletado (Nieminski \& Ongerth, 1995 , apud LeChevalier \& AK, 2004).

Todavia, algumas questões tendem a fragilizar a importância da turbidez como balizador da eficiência do tratamento, intrinsecamente relacionadas às diferenças existentes nos turbidímetros. Recente estudo (Teixeira et al, 2004) enfocando a confiabilidade analítica, em termos de turbidez, dos efluentes de duas unidades de filtração em escala-piloto, concluiu que as determinações de turbidez estão condicionadas aos distintos princípios de funcionamento dos equi- pamentos. As determinaçôes médias de turbidez com o emprego do equipamento de bancada $(1,0474 \pm 0,3664 \mathrm{uT})$ superaram em quase $30 \%$ às obtidas com o de escoamento contínuo $(0,8097 \pm$ 0,2834 uT), fator de maior importância para água filtrada de acordo com a mencionada recomendação da Portaria 518 (MINISTÉRIO DA SAÚDE, 2004).

Apesar das limitações, a turbidez permanece como um parâmetro importante e mais extensivamente utilizado no Brasil e no exterior no controle do processo de tratamento. Funciona bem como um indicador relativo da performance do tratamento e como um indicador grosseiro da qualidade da água.

Em 1988 iniciou-se, nos Estados Unidos e Canadá, o desenvolvimento de um método de otimização de estações de tratamento de água com respeito à proteção contra patógenos. O CCP - Composite Correction Program - permitia que estaçóes fizessem uso efetivo de seus processos e operaçôes unitárias aumentando a eficiência das barreiras contra a passagem de microrganismos. Alguns objetivos foram estabelecidos para definir a performance ótima da decantação, filtração e desinfecção. O efluente de cada decantador deveria atingir turbidez máxima de $2 \mathrm{uT}$ e dos filtros $0,1 \mathrm{uT}$, sendo tolerado um pico, após a lavagem da unidade filtrante, de até 0,3 u T por no máximo 15 minutos (USEPA, 1998).

Os conceitos de otimização introduzidos pelo CCP foram expandidos para diversas outras atividades de regulamentação e industriais. O programa Partnership for Safe Water, destinado a melhorar o tratamento para obtenção de água com melhor qualidade, utilizou o CCP como base para o desenvolvimento de sua fase III. Este programa foi desenvolvido pela associação de 6 entidades dos Estados Unidos e, em maio de 1998, 217 estações abastecendo 90 milhões de pessoas participavam do programa (GUIDELINES FOR PHASE IV, 2003).

Em 1984 o DEP - Department of Environmental Protection - do estado da Pennsylvania para assegurar a qualidade da água distribuída iniciou a implantação do programa FPPE - Filter Plant Performance Evaluation - cujo objetivo era determinar a efetividade da estação em remover partículas na mesma faixa de tamanhos dos cistos e oocistos de protozoários. Em 85 das 290 estações avaliadas até 1996 , os avaliadores do DEP utilizaram turbidímetros e contadores de 
partículas conectados a um ponto de amostragem do efluente dos filtros. Estes armazenaram os dados em um computador portátil durante 24 horas permitindo o traçado do perfil de turbidez e contagem de partículas destas estações. Em 1988 mais de $60 \%$ dos dados das estaçōes produziam água filtrada com turbidez maior que 0,2 uT, em 1996 este valor reduziu-se para somente $4 \%$.

Durante os 506 FPPE realizados em 290 unidades até o ano de 1996 foram levantados as dez falhas mais comuns: (i) Jar test realizado de forma inadequada ou falta de estratégia de controle do coagulante, (ii) operação de mistura rápida inadequada, (iii) falta de monitoramento individual dos filtros, (iv) tempo inadequado de descarte de água após a lavagem dos filtros, (v) ausência de calibração dos turbidímetros, (vi) dosagens inadequadas, (vii) conhecimentos de operação e manutenção insuficientes, (viii) filtração iniciada com o filtro sujo, (ix) monitoramento inadequado, (x) utilização somente da duração da carreira de filtração para a determinação do momento de lavagem dos filtros.

Após este período de experiência, alguns conceitos do Programa e do CCP foram introduzidos no FPPE. Passou-se a realizar a avaliação da capacidade de cada unidade do tratamento, além de se utilizar planilhas padronizadas para obtenção de séries temporais para a turbidez da água bruta, decantada e filtrada. Por meio da comparação destes gráficos pôde-se avaliar a capacidade da estação em produzir água de boa qualidade apesar da variabilidade da água bruta (Consonery et al, 1997).

Programas semelhantes podem ser aplicados ao Brasil, principalmenteembora não só - pelas companhias estaduais de saneamento responsáveis por operarem diversas estação de tratamento de água nos respectivos estados. Além do atendimento ao padrão de potabilidade, um indicador mais amplo de performance tornaria o critério de seleção das estações mais abrangente.

\section{Metodologia Delphi}

O conceito do método Delphi pode ser compreendido como o produto de um projeto da Rand Corporation, iniciado na década de 1950, a respeito da utilização da opinião de especialistas. $\mathrm{O}$ objetivo deste estudo era obter o mais significativo consenso de opinião sobre a seleção de uma meta ótima para o sistema industrial dos Estados Unidos estabelecendo uma estimativa do número de bombas atômicas necessário. Este consenso deveria ser obtido por meio da aplicação de uma série intensa de questionários mesclados com envios de feedback. A partir deste primeiro estudo, o Delphi passou a ser aplicado em uma ampla variedade de projetos nas mais diversas áreas.

Algumas características definem o método em questão: (i) o anonimato, com a finalidade de reduzir fatores psicológicos; (ii) a interação, por meio das várias rodadas de questionários permitindo aos participantes revisarem suas decisóes; (iii) o feedback, controlado entre duas rodadas de questionários para informar cada membro do grupo da opiniāo dos demais; (iv) a representação estatística dos resultados (Linstone \& Turoff, 1975).

Taylor e Ryder (2003) utilizaram a metodologia Delphi para coletar informações de especialistas visando plano de gerenciamento de 25 reservatórios de múltiplos usos. Estas informaçōes eram basicamente acerca dos níveis necessários à sobrevivência da ictiofauna. Questionários foram elaborados para cada reservatório e enviados a 26 especialistas, sendo que o número de respondentes por reservatório variou de 2 a 8 , podendo um único especialista responder os questionários referentes a mais de um reservatório. A pesquisa obteve $85 \%$ de retorno dos questionários e alta convergência das opiniōes para todos os reservatórios. As informações obtidas constituíram significante componente para o desenvolvimento de um modelo de auxílio-adecisão no gerenciamento destes reservatórios. Com isto a pesquisa demonstrou que o método Delphi pode ser utilizado para obter informações importantes para o gerenciamento de complexas questóes ambientais.

\section{Desenvolvimento de índices}

A transformação da interpretação de dados e parâmetros referentes ao funcionamento de estaçóes de tratamento de água em informação capaz de ser entendida pelo público em geral não é uma tarefa fácil. No entanto, também não é um problema restrito à área em questão. Há um grande número de tentativas de reproduzir em único valor o significado de um conjunto de dados.

Brown et al (1970), visando o desenvolvimento do IQA (Índice de Qualidade da Água), utilizou a metodologia
Delphi para estruturar a opinião de um grupo de 142 profissionais da área de qualidade da água. Esta pesquisa foi composta por 3 questionários. No primeiro foi enviada uma lista com 35 parâmetros selecionados arbitrariamente para possível inclusão em um índice de qualidade da água. Os participantes deveriam selecionar para cada parâmetro uma das opçōes Incluir, Não Incluir ou Indeciso, sendo possível listar outros parâmetros não incluídos nesta primeira lista. Cada parâmetro selecionado com o item Incluir deveria receber um peso variando de 1 a 5. Os resultados desta primeira rodada de questionários foi enviada aos participantes junto com o $2^{\circ}$ questionário para que estes comparassem suas respostas com a do grupo e as reavaliassem, também foi solicitada uma lista dos 15 parâmetros mais importantes. No terceiro questionário coube ao painelista desenhar, para 9 parâmetros selecionados, curvas que segundo seu julgamento representassem a variação da qualidade da água produzida pelas várias possíveis medidas do parâmetro. As nove curvas utilizadas para o calculo do IQA foram as curvas médias obtidas das respostas de todos os respondentes.

No País, a Cetesb (1980), diante da necessidade de se estabelecer métodos padronizados para avaliar o desempenho das estaçôes de tratamento ou dos processos e operaçôes unitárias que destas façam parte, desenvolveu um manual com finalidade de fornecer instrumentos para que engenheiros encarregados de operar sistemas estabelecessem controles de eficiência e desempenho. Os métodos de avaliação propostos foram divididos em rotineiros e extraordinários. Os rotineiros referiam-se a métodos a serem utilizados periodicamente nas estaçôes constituindo uma rotina de controle, objetivando, por exemplo, avaliar a eficiência da coagulação-floculação. Os métodos de avaliação de desempenho extraordinários seriam realizados ocasionalmente e, portanto, não constituiriam uma rotina de controle. Referiam-se principalmente a certas operaçōes ou processos nos quais modificaçōes faziam-se necessárias para uma melhora do funcionamento das unidades. Todavia, para o cálculo de praticamente todos os indicadores é necessária a realização de ensaios e nenhum destes indicadores apresenta uma avaliação do desempenho global da estação o que inviabiliza a utilização destes para comparar o desempenho das estações. 


\section{METODOLOGIA}

O presente trabalho pode ser definido como uma pesquisa aplicada, uma vez que visou fornecer uma ferramenta qualitativa, para auxiliar os administradores de sistemas de abastecimento, e quantitativa, pois classificará o desempenho de estações por meio de métodos numéricos. $\mathrm{O}$ universo deste trabalho limitou-se a estações com tecnologia convencional de tratamento, dotadas de decantadores de escoamento horizontal, potabilizando água bruta com características típicas da região Sudeste, para produção de efluente com turbidez inferior a 0,5 uT e ausência de coliformes totais conforme o padrão de potabilidade.

A metodologia para a elaboração do IQETA fundamentou-se basicamente na mesma utilizada por Brown et al (1970) para o desenvolvimento do IQA. Com isso após a determinação dos parâmetros constituintes do índice, bem como dos pesos atribuídos a cada parâmetro e dos critérios de pontuação, serão realizados um somatório e um produtório conforme as equaçóes (1) e (2) respectivamente:

$$
\begin{aligned}
& \text { IQETA }=\sum_{\mathrm{i}=1}^{\mathrm{N}}\left(\sum_{\mathrm{j}=1}^{\mathrm{n}} \mathrm{WjQj}\right)_{\mathrm{i}} \\
& \text { [QETA }=\prod_{\mathrm{i}=1}^{\mathrm{N}}\left(\prod_{\mathrm{j}=1}^{\mathrm{n}} \mathrm{Q}_{\mathrm{j}}^{\mathrm{Wj}}\right)_{\mathrm{i}}
\end{aligned}
$$

nas quais:

$\mathrm{Wj}$ = peso conferido a cada parâmetro definido por meio de uma pesquisa de opinião junto a especialistas;

$\mathrm{Qj}$ = nota atribuída à estação para cada parâmetro selecionado segundo um critério desenvolvido; índice;

$\mathrm{j}$ = cada parâmetro incluído no

$\mathrm{i}$ = cada grupo que irá constituir o índice-Mistura rápida, Floculação, Filtração, Decantação, Desinfecção e Operação;

$\mathrm{n}=$ número de parâmetros incluídos em cada grupo;

$\mathrm{N}$ = número total de grupos que constituirão o índice.

A metodologia utilizada para o desenvolvimento do IQETA dividiu-se em 3 etapas a serem detalhadas a seguir.

\section{Pesquisa de opinião}

Para a determinação dos parâmetros intervenientes serem incluídos no IQETA, bem como seus respectivos pesos, foi realizada uma pesquisa de opinião junto a 18 especialistas da área, sendo que 16 se mantiveram até o término da pesquisa. $\mathrm{O}$ grupo foi selecionado de forma a minimizar a influência de opinião baseada em um único tipo de profissional ou região geográfica do País.

Esta pesquisa foi constituída de 2 fases elaboradas de acordo com as características do método Delphi. Após a revisão da literatura sobre a tecnologia convencional de tratamento, foi elaborada uma primeira lista de parâmetros intervenientes na potabilização da água por meio desta tecnologia apresentada na Tabela 1.
Esta lista foi utilizada na elaboração do primeiro questionário enviado aos 18 painelistas selecionados. O painel foi composto por profissionais de nível superior responsáveis por pesquisas, projetos e operação de estações de tratamento de água, abarcando universidades, companhias estaduais de saneamento e empresas de engenharia das regiōes Sul e Sudeste, compreendendo os estados de RS, SC, MG, SP e PR, sendo apresentado na Tabela 2 a distribuição dos 16 painelistas que permaneceram até o término da pesquisa.

O primeiro questionário foi composto de três partes. A primeira trata-se de uma introdução explicando todas as etapas do trabalho, situando o painelista no processo no qual foi inserido. A segunda apresenta as instruções para o preenchimento e a terceira é constituída pela lista dos parâmetros inicialmente levantados, os quais deveriam ser julgados por meio das opções incluir no indice, não incluir e indeciso, podendo o participante adicionar novos parâmetros não constantes do questionário inicial. Após julgar os parâmetros, cada respondente atribuiria pesos de até 100 somente para os parâmetros selecionados com o item incluir.

Após o encerramento da $1^{\text {a }}$ fase foi elaborado um relatório contendo uma tabela com sumário numérico das respostas de todos painelistas - percentagem de inclusão, média, moda, mediana e amplitude inter-quartílica -, resumo dos comentários listados pelos respondentes, as respostas do painelista e uma coluna para reavaliação das respostas. Foi solicitado

\begin{tabular}{|c|c|c|c|}
\hline $\mathrm{G}_{\mathrm{MR}}$ & Gradiente de velocidade da mistura rápida & 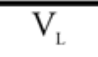 & Velocidade longitudinal de escoamento \\
\hline $\mathrm{T}_{\mathrm{MR}}$ & Tempo de Agitação da Mistura Rápida & $\mathrm{Q}_{\mathrm{L}}$ & $\begin{array}{l}\text { Vazão linear de coleta de água } \\
\text { decantada }\end{array}$ \\
\hline Jtest & Realização de ensaios de Jar Test & $\mathrm{T}_{\text {filt }}$ & Taxa de filtração \\
\hline $\mathrm{G}_{\mathrm{f}}$ & Gradiente de velocidade da floculação & Dcarr & Duração da carreira de filtração \\
\hline $\mathrm{T}_{\mathrm{f}}$ & Tempo de floculação & Exp & Expansão do leito filtrante \\
\hline$\square \mathrm{p}$ & Gradiente de velocidade nas passagens entre câmaras & Vasc & Velocidade ascencional de lavagem \\
\hline Nc & Número de câmaras & $\mathrm{L}_{\mathrm{ar}}$ & Lavagem auxiliar com ar \\
\hline$V_{c}$ & $\begin{array}{l}\text { Velocidade média de escoamento no canal de água } \\
\text { floculada }\end{array}$ & $\mathrm{L}_{\text {igua }}$ & Lavagem auxiliar com água \\
\hline Gcom & $\begin{array}{l}\text { Gradiente de velocidade nas comportas de acesso ao } \\
\text { Decantador }\end{array}$ & Tc & $\begin{array}{l}\text { Tempo de detençăo no tanque de } \\
\text { contato }\end{array}$ \\
\hline Gcor & $\begin{array}{l}\text { Gradiente de velocidade através dos orifícios da cortina de } \\
\text { distribuiçấo de água floculada }\end{array}$ & Nch & $\begin{array}{l}\text { Número de chicanas no tanque de } \\
\text { contato }\end{array}$ \\
\hline Vs & Velocidade de sedimentação ou taxa de aplicação superficial & GI & $\begin{array}{l}\text { Grau de instrução da equipe de } \\
\text { operação }\end{array}$ \\
\hline
\end{tabular}

Tabela I - Parâmetros incluídos no primeiro questionário 
Tabela 2 Distribuição dos painelistas

\begin{tabular}{lcc}
\multicolumn{1}{c}{\begin{tabular}{c} 
Função exercida pelo \\
\multicolumn{1}{c}{ participante }
\end{tabular}} & \multicolumn{2}{c}{ Regiōes } \\
\hline Operador & Sudeste \\
Projetista & 2 & 2 \\
Pesquisador & 1 & 2 \\
Pesquisador/Projetisa & & 6 \\
Projetista/Operador & & 1 \\
Pesquisador/Operador & & 1 \\
\hline
\end{tabular}

que, após uma avaliação sobre as conclusões do grupo, os painelistas revisassem seus pontos de vista mantendo ou modificando as respostas do primeiro questionário.

Os parâmetros incluídos no índice foram divididos em seis grupos conforme o processo ou operação unitária do tratamento convencional de água ao qual se refiram, como por exemplo, nos grupos Mistura Rápida, Floculação, Sedimentação, Filtração, Desinfecção e Operação. A partir dos pesos atribuídos aos parâmetros foi determinado o peso de cada grupo para o desempenho eficiente do tratamento. $\mathrm{O}$ motivo desta separação em grupos foi a possibilidade de se ter um índice para o tratamento como um todo, formado a partir de índices de cada processo ou operação. Assim, será possível identificar qual grupo está sendo responsável pela eventual baixa pontuação da estação de tratamento.

\section{Desenvolvimento dos critérios de pontuação}

Após a definição dos parâmetros incluídos no índice e dos seus respectivos pesos partiu-se para a segunda etapa do trabalho. Nesta foram estabelecidos os critérios de pontuação, baseados nas premissas estabelecidas pela ABNT (1989) e por valores referenciados na literatura.

\section{Aplicação do IQETA a estaçóes de tratamento de água}

A etapa final deste trabalho compreendeu a realização de um estudo comparativo entre a nota total atribuída pelo índice a uma determinada estação de tratamento com os dados de monitoramento referentes aos valores da turbidez da água filtrada.O escopo desta última etapa foi escolher uma fórmula de cálculo para o índice - somatório ou produtório - e verificar a validade do valor atribuído pelo índice ao tratamento, ou seja, se a unidade potabilizadora avaliada com um IQETA elevado possuía também bom desempenho realizado pela análise dos dados da operação referentes à turbidez da água filtrada.

Para tal, o índice desenvolvido, nas formas de somatório e produtório, foi aplicado à avaliação do desempenho de 10 estaçóes convencionais de tratamento de água dos estados de Minas Gerais e São Paulo. A seleção das estações foi realizada de acordo com a facilidade de acesso e a consistência dos dados de monitoramento fornecidos.

Para a realização da comparação do IQETA com os valores de turbidez para a água filtrada foram elaboradas tabelas nas quais constavam o dia, os valores do IQETA somatório e produtório e os valores médios da turbidez da água filtrada para seis meses de dados - três meses do período seco e três meses do período chuvoso, referentes a 2003 e 2004 . Foram então calculados os seguintes valores para cada um dos períodos, definidos de acordo com recomendaçôes dos padrões de potabilidade brasileiro e norte-americano:

- \% do tempo no qual o valor da turbidez era mantido $\leq 0,5 \mathrm{uT}$;

- \% do tempo no qual o valor da turbidez era mantido $\leq 0,3 \mathrm{uT}$;

- \% do tempo no qual o valor da turbidez era mantido $\leq 0,1 \mathrm{uT}$;

- Valor abaixo do qual se encontram 95\% dos valores da turbidez.

De posse destes valores foram elaborados diagramas de dispersão com as medianas do IQETA, para cada período em questão e estação, no eixo das abscissas, e um dos valores citados acima para cada estação no eixo das ordenadas. Ressaltase que a percentagem do tempo no qual a turbidez era $\leq 1 \mathrm{u}$ T não foi incluído na análise devido ao fato de todas as estações cumprirem esta meta para o período seco e praticamente todas para o período chu- voso. Além disso, esta exigência torna estes valores duvidosos induzindo, em alguns casos, o operador a preencher as planilhas com valores abaixo ou iguais a $1 \mathrm{uT}$ quando estes foram na realidade maiores.

Posteriormente, foram calculados os coeficientes de correlação linear e não-linear com a intenção de verificar se o IQETA se correlacionava com os valores da turbidez da água filtrada, ou seja, se uma piora no valor do índice era seguida de uma piora da qualidade da água filtrada em termos de turbidez.

Uma última análise utilizada para verificar a validade do IQETA foi baseada na premissa de que uma estação possuindo bom desempenho deverá ser capaz, mesmo quando recebendo água bruta de qualidade variável, fornecer água tratada de qualidade constante, ou seja, a qualidade da água tratada não deverá se alterar com a variação da turbidez da água bruta. Para avaliar se o IQETA apresentava melhores pontuações para as estações trabalhando de acordo com esta assertiva foram calculadas as correlaçôes ( $\mathrm{r}$ ) entre as águas brutas, decantadas e filtradas.

\section{RESULTADOS}

\section{Respostas dos painelistas e definição dos pesos de cada parâmetro}

A $1^{\text {a }}$ rodada da pesquisa teve uma duração total de 4 meses - janeiro a abril de 2004 - apresentando uma abstenção de $11 \%$ em relação aos 18 questionários enviados. Durante esta etapa os questionários foram impressos e enviados aos painelistas por meio de carta. Já na 2a rodada, cuja duração foi de aproximadamente 3 meses - junho a agosto de 2004 -, a abstenção foi $6 \%$ entre os 17 questionários enviados. Nesta, os questionários foram enviados por via eletrônica devido à necessidade de maior rapidez no recebimento das respostas e a manifestação da preferência de alguns painelistas por esta forma de envio.

As justificativas e comentários na primeira rodada foram enviadas aos painelistas durante a segunda. Estas tinham a finalidade de tentar apresentar ao respondente o ponto de vista dos outros colegas. Nenhum dos parâmetros inseridos na primeira rodada (Tabela 1) foi descartado, e dos incluídos pelos painelistas igualmente nenhum foi adicionado à listagem do $2^{\circ}$ questionário, ou por não se considerar as informaçôes refe- 
rentes a estes de fácil acesso ou por serem muito subjetivos. Por exemplo, foi sugerida a inclusão dos seguintes parâmetros: sinais visiveis de retromistura, estado geral da casa de química, versatilidade da planta, residuais de coagulante e outros. As sugestões de parâmetros referentes à qualidade da água bruta não foram acatadas devido ao índice em desenvolvimento ter como finalidade avaliar tão-somente o tratamento, independente das características da água bruta. Além disso não houve nenhuma sugestão de novo parâmetro corroborada por mais de três painelistas.

Como já mencionado, os painelistas foram instruídos a pontuarem até 100 pontos os parâmetros selecionados com a opção Incluir. Este sistema de pontuação foi adotado visando facilitar o preenchimento dos questionários, uma vez que, caso se solicitasse distribuir um total de 100 pontos entres os parâmetros, os participantes levariam mais tempo para preencher os questionários e este fato poderia aumentar a taxa de abstinência. No entanto, para o escopo deste trabalho acredita-se ser relevante a importância relativa de cada parâmetro, ou seja, o peso conferido a um parâmetro por cada painelista em relação ao total de pontos distribuídos por ele. Por isto a pontuação de cada parâmetro foi divida pelo total distribuído pelo painelista, de forma a todos os pesos distribuídos totalizassem 100 pontos.

$\mathrm{Na}$ Figura 1 pode-se observar a importância atribuída a cada parâmetro dentro do processo de avaliação do desempenho global da estação. De acordo com o conjunto dos especialistas a taxa de filtração confirmou-se como o parâmetro mais relevante, responsável por aproximadamente $9 \%$ do desempenho da unidade, consoante tendências dos padrôes de potabilidade nacionais e internacionais de privilegiar a redução da turbidez da água filtrada. A velocidade de sedimentação e o gradiente de floculação, junto com a taxa de filtração, foram considerados responsáveis por aproximadamente $23 \%$ do desempenho da estação. $\mathrm{O}$ primeiro representando a importância da garantia da sedimentabilidade dos flocos e o segundo a adequada formação destes.

Pela observação das barras verticais pode-se verificar que os parâmetros de maior peso foram justamente os causadores das maiores disparidades nas respostas dos questionários, indicando concordância entre os painelistas sobre a importância destes para o desempenho, mas grande discordância acerca do peso a ser conferido.

Diante dos resultados, os pesos para o cálculo do IQETA deveriam ser então definidos. E como defini-los diante da grande dispersão dos resultados? Talvez outras rodadas de questionários pudessem levar a uma maior convergência dos resultados, porém esta opção mostrou-se inviável devido ao tempo despendido com cada rodada. Além de não se esperar grandes alteraçôes, pois muitos painelistas efetuaram apenas pequenas alteraçóes nos pontos distribuídos e outros mantiveram seus pontos de vista inalterados. Com isso, duas decisões foram tomadas para a definição dos pesos finais: (i) para evitar a influência dos pontos extremos optou-se por definir a mediana dos pontos recebidos - após a já citada transformação - para cada parâmetro, como melhor medida da opiniāo do grupo; (ii) nenhum parâmetro

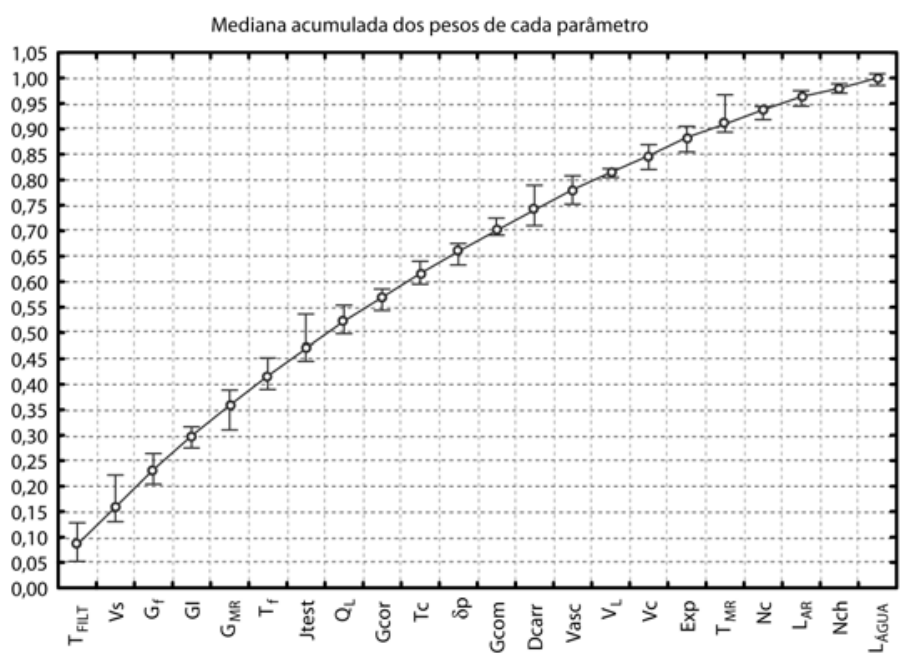

Figura I- Hierarquização dos parâmetros foi excluído, sendo os pesos multiplicados pela taxa de inclusão, assim os com $100 \%$ de inclusão tiveram seus pesos mantidos e os demais tiveram seus pesos diminuídos.

Por questóes relacionadas ao desenvolvimento dos critérios de pontuação alguns parâmetros foram unificados. Por exemplo, decidiu-se por pontuar os parâmetros $\mathrm{G}_{\mathrm{f}} \mathrm{e} \mathrm{T}_{\mathrm{f}}$ por par e não individualmente sendo o peso da pontuação do par igual à soma dos pesos individuais de cada um destes. Os parâmetros $\mathrm{L}_{\mathrm{ar}} \mathrm{e}$ $\mathrm{L}_{\text {água }}$ foram transformados em um único parâmetro denominado $\mathrm{L}_{\text {aux }}$ (Lavagem auxiliar), o peso deste parâmetro foi definido como a mediana de todos os pesos atribuídos a estes. Da mesma maneira foi definido o peso do agrupamento dos parâmetros Exp e Vasc, porém neste caso estes não foram transformados em um único parâmetro. Para cada estação devese escolher um dos dois para ser pontuado, ou pontua-se com o valor de Exp ou de Vasc, uma vez que a inclusão de ambos estaria sobrevalorando um mesmo aspecto relacionado à lavagem do meio filtrante.

Por fim, uma última transformação foi realizada, dividindo-se cada peso pelo total para que todos somassem 1 e o peso final de cada parâmetro encontra-se na Tabela 3.

\section{Desenvolvimento dos critérios de pontuação}

Após a definição dos pesos atribuídos a cada parâmetro houve necessidade de também estabelecer os critérios de pontuação. Na realidade, esta definição substitui as curvas traçadas por cada painelista quando da elaboração do IQA. Nesta etapa os parâmetros, conforme mencionado na metodologia, foram divididos nos grupos Mistura Rápida, Floculação, Sedimentação, Filtração, Desinfecção e Operação.

Dos 19 parâmetros, optou-se por detalhar, pela sua relevância (o segundo parâmetro após a taxa de filtração), apenas a velocidade de sedimentação do grupo concernente à decantação. A esta unidade cabe remover pela ação da gravidade os flocos formados nas etapas anteriores diminuindo o aporte de partículas aos filtros. Dentre os fatores intervenientes na eficiência desta operação destacam-se a velocidade de sedimentação, as condições de entrada e saída e o procedimento de remoção do lodo sedimentado.

Devido às diferenças de tamanho, densidade e forma das partículas a de- 
Tabela 3 - Pesos

\begin{tabular}{|c|c|c|}
\hline Grupo & Parâmetro & Peso \\
\hline \multirow[t]{2}{*}{ Mistura rápida } & $\mathrm{G}_{\mathrm{MR}}$ & 0,06 \\
\hline & $\mathrm{T}_{\mathrm{MR}}$ & 0,03 \\
\hline \multirow[t]{4}{*}{ Floculação } & $\mathrm{G}_{\mathrm{f}}-\mathrm{T}_{\mathrm{f}}$ & 0,14 \\
\hline & $\square \mathrm{p}$ & 0,04 \\
\hline & $\mathrm{Nc}$ & 0,03 \\
\hline & $\mathrm{Vc}_{\mathrm{c}}$ & 0,03 \\
\hline \multirow[t]{5}{*}{ Decantação } & Gcom & 0,04 \\
\hline & Gcor & 0,05 \\
\hline & Vs & 0,08 \\
\hline & $\mathrm{V}_{\mathrm{L}}$ & 0,04 \\
\hline & $Q_{L}$ & 0,06 \\
\hline \multirow[t]{4}{*}{ Filtração } & $\mathrm{T}_{\text {filt }}$ & 0,09 \\
\hline & Dcarr & 0,04 \\
\hline & Exp/Vasc & 0,04 \\
\hline & $\mathrm{L}_{\text {aux }}$ & 0,03 \\
\hline \multirow[t]{2}{*}{ Desinfecção } & $\mathrm{Tc}$ & 0,05 \\
\hline & Nch & 0,02 \\
\hline \multirow[t]{2}{*}{ Operação } & Jtest & 0,07 \\
\hline & GI & 0,06 \\
\hline
\end{tabular}

cantação apresenta grande dificuldade de ser descrita. Com isso o modelo do decantador ideal de escoamento horizontal, apesar de simplista, foi utilizado para se prever o comportamento das partículas. Algumas suposiçōes simplificativas caracterizam este modelo: (i) dentro da zona de sedimentação, as partículas sedimentam de forma análoga a em um recipiente em repouso de mesma profundidade; (ii) o escoamento e a concentração das partículas em suspensão são uniformes em toda seção transversal; (iii) não há ressuspensão quando os flocos atingem a zona de lodos.

A pontuação foi definida a partir da relação Vs'/Vs, considerando Vs igual a uma taxa de aplicação sofrendo incremento de $5 \%$ a partir da taxa de projeto e, Vs igual a taxa de aplicação de projeto. Evidentemente, todas estaçóes cujos decantadores operavam com taxas inferiores às preconizadas pela ABNT(1989) receberam pontuação máxima.

Em um decantador real a velocidade de sedimentação das partículas tende a aumentar à medida que estas, devido à sedimentação diferencial, se agruparem em flocos maiores. Com isso a eficiência de remoção será maior do que a calculada compensar os demais efeitos negativos, o critério de pontuação para a Vs, apresentado na Figura 2, utilizou-se apenas do modelo ideal já descrito.

\section{Aplicação do IQETA}

Por fim, com os pesos e os critérios de pontuação definidos, a última etapa desta pesquisa constou de uma aplicação do IQETA nas formas de produtório e somatório - equaçōes (1) e (2) - a 10 estaçôes de tratamento de água de médio e grande porte localizadas nos estados de Minas Gerais e São Paulo. As estaçôes não foram identificas uma vez que o cerne deste trabalho é discutir a aplicabilidade do índice desenvolvido e não emitir qualquer opiniāo acerca do desempenho das estaçōes, cujos responsáveis prontamente cederam seus dados de operação permitindo a realização do trabalho.

Como o período de dados, referentes às estações, variou de 6 meses a um ano não foi possível utilizar o período de um ano para a avaliação das estaçōes, por isto foram considerados 3 meses para o período chuvoso e 3 meses para o período seco. Sempre que possível, os dados referentes aos meses de janeiro a março foram considerados para o período chuvoso e os de junho a agosto para o período seco. O exemplo do cálculo do IQETA de uma das estações é apresentado na Tabela 4.

Após o cálculo dos dois IQETA, o principal ponto passou a ser a definição pelo produtório ou somatório. A distinção entre ambas equaçōes reside no fato de uma estação que apresente pontuação baixa para um parâmetro, por exemplo, terá sua nota final afetada mais significantemente quando for utilizada a res e considerando que os efeitos positivos da sedimentação diferencial possam com o modelo ideal citado anteriormente. Em oposição à sedimentação diferenquebra dos flocos e ressuspensão do lodo sedimentado prejudicando o desempenho desta unidade. Devido à dificuldade de equacionar a influência destes fato-

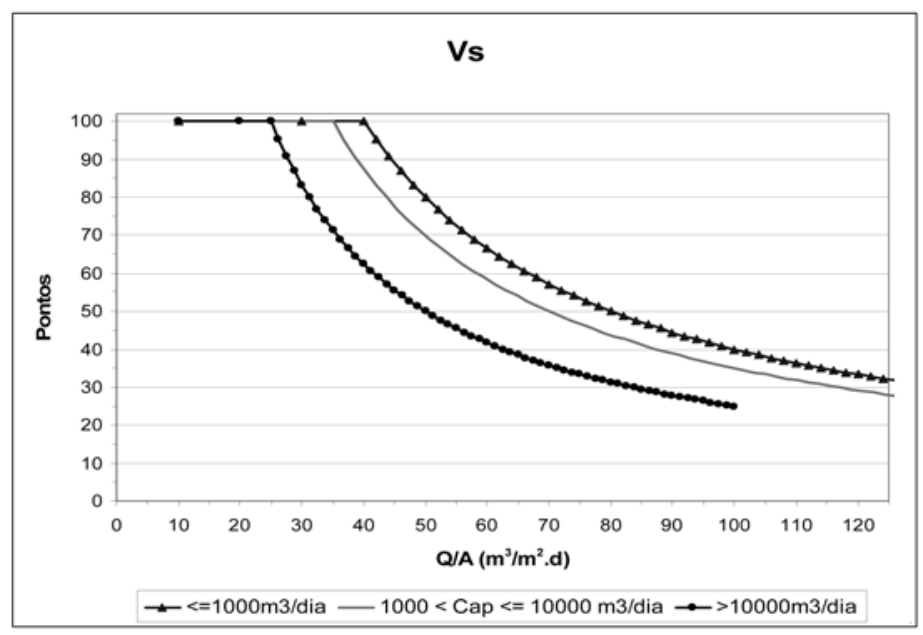

Figura 2 - Critério de pontuação desenvolvido para Vs 
Tabela 4 - Exemplo de cálculo do IQETA para uma das estações do universo amostral

\begin{tabular}{|c|c|c|c|c|c|c|c|c|}
\hline Grupo & Parâmetro & $\begin{array}{c}\text { Mediana dos } \\
\text { valores de cada } \\
\text { parâmetro de } \\
\text { dados diários para } \\
6 \text { meses }\end{array}$ & Pontos & Pesos & $\begin{array}{l}\text { Pesos } \mathrm{x} \\
\text { Pontos }\end{array}$ & $\begin{array}{c}\text { Pesos } \\
\wedge \\
\text { Pontos }\end{array}$ & $\begin{array}{l}\text { Pontos } \\
\text { por } \\
\text { grupo- } \\
\text { Som }\end{array}$ & $\begin{array}{l}\text { Pontos } \\
\text { por } \\
\text { grupo- } \\
\text { Prod }\end{array}$ \\
\hline \multirow{2}{*}{$\begin{array}{l}\text { Mistura } \\
\text { rápida }\end{array}$} & $\mathrm{G}_{\mathrm{MR}}\left(\mathrm{s}^{-1}\right)$ & 1340,65 & 100 & 0,06 & 6,00 & 1,32 & 9,00 & 1,52 \\
\hline & $\mathrm{T}_{\mathrm{MR}}(\mathrm{s})$ & 0,40 & 100 & 0,03 & 3,00 & 1,15 & & \\
\hline \multirow[t]{6}{*}{ Floculação } & $G_{F}\left(s^{-1}\right)$ & 35,18 & 30 & 0,14 & 4,20 & 1,61 & 9,04 & 2,09 \\
\hline & $\mathrm{T}_{\mathrm{F}}(\mathrm{s})$ & 835,87 & & & & & & \\
\hline & Tipo de floculador & Hidráulico & & & & & & \\
\hline & $\square \mathrm{p}\left(\mathrm{s}^{-1}\right)$ & 55,11 & 1 & 0,04 & 0,04 & 1,00 & & \\
\hline & $\mathrm{Nc}$ & 5 & 60 & 0,03 & 1,80 & 1,13 & & \\
\hline & $\mathrm{V}_{\mathrm{c}}(\mathrm{m} / \mathrm{s})$ & 0,29 & 100 & 0,03 & 3,00 & 1,15 & & \\
\hline \multirow[t]{5}{*}{ Decantação } & Gcom (s-1) & 19,29 & 100 & 0,04 & 4,00 & 1,20 & 25,24 & 3,40 \\
\hline & Gcor $(s-1)$ & 8,19 & 100 & 0,05 & 5,00 & 1,26 & & \\
\hline & $\mathrm{Vs}(\mathrm{cm} / \mathrm{min})$ & 3,02 & 80 & 0,08 & 6,40 & 1,42 & & \\
\hline & $\mathrm{V}_{\mathrm{L}}(\mathrm{cm} / \mathrm{s})$ & 0,26 & 100 & 0,04 & 4,00 & 1,20 & & \\
\hline & $\mathrm{Q}_{\mathrm{L}}(\mathrm{L} / \mathrm{s} . \mathrm{m})$ & 1,64 & 100 & 0,06 & 6,00 & 1,32 & & \\
\hline \multirow[t]{4}{*}{ Filtração } & $\begin{array}{l}\text { Tipo de filtro } \\
\text { Tfilt (m/dia) }\end{array}$ & $\begin{array}{c}\text { Descendente-leito } \\
\text { duplo } \\
279,66\end{array}$ & 100 & 0,09 & 9,00 & 1,51 & 17,03 & 2,17 \\
\hline & $\begin{array}{l}\text { Dcarr - Volume } \\
\text { filtrado }\left(\mathrm{m}^{3} / \mathrm{m}^{2} / \text { carreira }\right) \\
\text { Volume de água de } \\
\operatorname{lav}\left(\mathrm{m}^{3} / \mathrm{m}^{2} / \text { filtro }\right)\end{array}$ & $\begin{array}{c}475,30 \\
6,06\end{array}$ & 100 & 0,04 & 4,00 & 1,20 & & \\
\hline & $\operatorname{Exp}(\%)$ & 32 & 100 & 0,04 & 4,00 & 1,20 & & \\
\hline & Laux & $\begin{array}{c}\text { Manual, com água } \\
\text { e lavagem } \\
\text { superficial } \\
\text { (rastelamento) }\end{array}$ & 1 & 0,03 & 0,03 & 1 & & \\
\hline \multirow[t]{4}{*}{ Desinfecção } & $\mathrm{Cl}$ residual $(\mathrm{mg} / \mathrm{L})$ & 0,87 & 10 & 0,05 & 0,5 & 1,12 & 1,5 & 1,21 \\
\hline & $\mathrm{Tc}(\min )$ & 1,47 & & & & & & \\
\hline & $\mathrm{pH}$ & $\leq 7$ & & & & & & \\
\hline & Nch & $\begin{array}{l}\text { A água entra na } \\
\text { parte inferior do } \\
\text { tanque, recebe o } \\
\text { cloro, verte por } \\
\text { uma chicana na } \\
\text { parte superior. } \\
\text { Superior }\end{array}$ & 100 & 0,07 & 7,00 & 1,38 & 13 & 1,82 \\
\hline Operação & Jar test & $\begin{array}{l}\text { Dependendo da } \\
\text { variação da } \\
\text { turbidez da água } \\
\text { bruta }\end{array}$ & 100 & 0,06 & 6,00 & 1,32 & & \\
\hline IQETA & & & & & & & 74,81 & 51,62 \\
\hline
\end{tabular}


equação do produtório, mais sensível a variações. Já as estaçóes portadoras de pontuaçóes mais ou menos equivalentes para todos os parâmetros mantiveram seus índices aproximadamente constantes independente da equação utilizada para o cálculo. A questão, cuja resposta pretende-se alcançar por meio das análises a seguir e com a qual se tenciona justificar a escolha pela forma de cálculo, é: será que apenas um parâmetro com pontuação baixa causa um impacto significativo no desempenho global da estação capaz de justificar a opção pelo produtório?

Para avaliar a aplicabilidade do índice, os valores deste foram comparados com a turbidez da água filtrada. Esta comparação efetuou-se por meio da realização de gráficos de dispersão e cálculo de correlação entre o IQETA, na forma de somatório e produtório, e porcentagem de valores médios diários da turbidez da água filtrada menores que $0,5 \mathrm{uT}$ e 0,3 uT. Também foram elaborados gráficos comparando os índices com o valor abaixo do qual estão $95 \%$ dos valores da turbidez da água filtrada. E, para a confirmação da correlação encontrada foi realizado um último gráfico plotando-se o valor médio diário da turbidez contra o IQETA médio diário. Todos os gráficos, com a exceção destes últimos, foram divididos em período seco e período chuvoso.

A correlação foi utilizada para medir o grau de associação entre a porcentagem de turbidez abaixo de um valor préestabelecido e o índice. A turbidez foi escolhida como balizador para a aplicabilidade do IQETA por, além de ser um indicador da eficiência do tratamento, praticamente todas as estaçóes disponibilizarem dados para este parâmetro.

Para uma melhor comparação dos valores obtidos, estes foram organizados na Tabela 5, destacando em negrito os resultados $\left(\mathrm{r}^{2}\right)$ mais significativos. Nesta também foi incluída a correlação do IQETA com os percentuais abaixo de 0,7 uT. Pode-se observar que, para o período chuvoso, o IQETA produtório apresentou resultados mais significantes quando comparado com a porcentagem de valores de turbidez da água filtrada menores ou iguais a 0,1 e a $0,3 \mathrm{uT}$ e com o valor abaixo do qual estão $95 \%$ dos dados Já o IQETA somatório apresentou valores com maior significância quando comparado com porcentagem dos valores menores ou iguais a 0,5 e a $0,7 \mathrm{uT}$. No período seco, os valores do IQETA correlacionaram-se com as porcentagens com altos valores de $\mathrm{p}$, o que leva a rejeitar a existência de correlação entre estas variáveis. No entanto enfatiza-se a existência de melhores resultados para o somatório.

Dos dados apresentados na Tabela 5 pode-se concluir o melhor desempenho do IQETA produtório quando as exigências em termos de turbidez foram mais restritivas e um melhor desempenho do IQETA somatório quando as exigências foram mais brandas.

Como o r mede somente a correlação linear entre as variáveis decidiu-se por calcular também o coeficiente de correlação denominado Tau de Kendall $(\tau)$, apresentado na Tabela 6 . Este coeficiente mede também a correlação não-linear existente entre duas variáveis além de ser mais resistente aos outliers. Os valores presentes na Tabela 6 demonstram melhor correlação para o IQETA produtório para o período chuvoso e também para o período seco. Sendo que no caso do período seco apresentou inclusive correlação com melhores níveis de significância.

Para o período seco, embora o $\mathrm{r}$ tenha sido maior para o IQETA somatório, em ambos os casos os valores de $\mathrm{p}$ foram muito elevados recomendando a rejeição da existência de correlação linear entre as

Tabela 5 - Coeficientes de relação linear ( $r$ )

Percentuais de valores de turbidez abaixo do limite estabelecido

Período Chuvoso

Período Seco

\begin{tabular}{|c|c|c|c|c|c|c|c|c|c|c|c|}
\hline & & $<=0,1 \mathrm{uT}$ & $<=0,3 \mathrm{uT}$ & $<=0,5 \mathrm{uT}$ & $<=0,7 \mathrm{uT}$ & $95 \%$ & $<=0,1 \mathrm{uT}$ & $<=0,3 \mathrm{uT}$ & $<=0,5 \mathrm{uT}$ & $<=0,7 \mathrm{uT}$ & $95 \%$ \\
\hline \multirow{3}{*}{$\begin{array}{l}\text { IQETA } \\
\text { Somatório }\end{array}$} & $\mathrm{R}$ & 0,37 & 0,55 & 0,80 & 0,85 & $-0,62$ & $-0,05$ & 0,33 & 0,47 & 0,48 & $-0,50$ \\
\hline & $\mathrm{R}^{2}$ & 0,14 & 0,30 & 0,63 & 0,73 & 0,38 & 0,00 & 0,11 & 0,22 & 0,23 & 0,25 \\
\hline & $\mathrm{P}$ & 0,37 & 0,16 & 0,02 & 0,01 & 0,10 & 0,90 & 0,39 & 0,21 & 0,20 & 0,17 \\
\hline \multirow{3}{*}{$\begin{array}{l}\text { IQETA } \\
\text { Produtório }\end{array}$} & $\mathrm{R}$ & 0,56 & 0,85 & 0,73 & 0,69 & $-0,86$ & 0,38 & 0,21 & 0,25 & 0,24 & $-0,23$ \\
\hline & $\mathrm{R}^{2}$ & 0,31 & 0,73 & 0,53 & 0,48 & 0,74 & 0,14 & 0,04 & 0,06 & 0,06 & 0,05 \\
\hline & $\mathrm{p}$ & 0,15 & 0,01 & 0,04 & 0,06 & 0,01 & 0,31 & 0,60 & 0,51 & 0,53 & 0,55 \\
\hline
\end{tabular}

Tabela 6 - Cálculo do $\tau$ de Kendall

\begin{tabular}{lrrrr}
\hline & \multicolumn{2}{c}{ P. Chuvoso } & \multicolumn{2}{c}{ P. Seco } \\
& Kendall $\tau$ & \multicolumn{1}{c}{$\mathrm{p}$} & Kendall $\tau$ & $\mathrm{p}$ \\
\hline IQETA S \& $<=0,3 \mathrm{uT}$ & 0,59 & 0,02 & 0,21 & 0,31 \\
IQETA S \& $<=0,5 \mathrm{uT}$ & 0,48 & 0,06 & 0,28 & 0,18 \\
IQETA S \& 95\% & $-0,50$ & 0,04 & $-0,22$ & 0,24 \\
IQETA P \& $<=0,3$ uT & 0,72 & 0,01 & 0,57 & 0,02 \\
IQETA P \& $<=0,5 \mathrm{uT}$ & 0,70 & 0,01 & 0,39 & 0,09 \\
IQETA P \& 95\% & $-0,83$ & $\mathrm{p}<.001$ & $-0,44$ & 0,06 \\
\hline
\end{tabular}


variáveis testadas. Já no caso do $\tau$, este foi mais significativo para o IQETA produtório demonstrando que embora não haja correlação linear entre as variáveis, há correlação não-linear entre estas. No entanto os melhores resultados para o IQETA somatório, em termos de $\mathrm{r}$ durante o período seco, não invalida a primeira conclusão, ou seja, o IQETA produtório demonstrou-se mais adequado ao período chuvoso, no qual são maiores as dificuldades em manter a qualidade da água filtrada.

Retomando a pergunta realizada no início desta discussão: será que apenas um parâmetro com pontuação ruim causa um impacto significativo no desempenho global da estação, em termos de remoção de turbidez, capaz de justificar a opção pelo produtório?

Pela análise realizada acredita-se que um único parâmetro, como por exemplo Vs ou Gcor, pode sim afetar o desempenho da estação, a ponto de se decidir por uma pontuação mais baixa ainda que todos os outros parâmetros estejam adequados. Esta decisão foi corroborada por maiores valores de correlação para o IQETA produtório quando critérios mais restritivos para a turbidez foram utilizados.

Posteriormente avaliou-se se o estabelecimento de metas para os valores de turbidez estariam induzindo a uma correlação entre estas e o IQETA. Para tal fim, elaboraram-se os gráficos de dispersão entre valores diários do IQETA e os valores médios diários para a turbidez da água filtrada para as 10 estaçôes e os 6 meses de dados, os já citados 3 meses chuvosos e 3 meses secos. Delineou-se uma correlação do IQETA com a turbidez da água filtrada, ligeiramente maior para o somatório no caso de correlação linear indicada por $r$ e ligeiramente maior para o produtório quando se considera também a correlação não-linear (Tabela 7).

Com a finalidade de se obter uma dimensão da correlação existente entre os valores das águas bruta e decantada e entre os valores das águas decantada e filtra$\mathrm{da}$, os coeficientes de correlação linear foram calculados para todas as estações sendo estes apresentados na Tabela 8. Ressalta-se que para a ETA I e ETA X não foram obtidos dados referentes à turbidez da água decantada e para a ETA III e
ETA IV idem para a turbidez da água filtrada, justificando as lacunas na tabela.

Acredita-se que estações com bom desempenho devam ser capazes de produzir água filtrada com qualidade constante, independente das características da água bruta. Diante desta afirmação e dos dados da citada tabela, a ETA VII apresentou melhores resultados para o desempenho da decantação e a ETA II os melhores resultados para o desempenho da filtração. Já a ETA IV e ETA IX.B apre-

Tabela 7 - Correlação entre a turbidez da água filtrada e o IQETA para a totalidade dos dados

\begin{tabular}{cccc}
\hline & $\mathrm{r}$ & $\mathrm{r}^{2}$ & $\tau$ \\
\hline IQETA S & $-0,47$ & 0,22 & $-0,37$ \\
IQETA P & $-0,39$ & 0,15 & $-0,42$ \\
\hline
\end{tabular}

Tabela 8 - Correlação entre os valores de turbidez das águas Bruta/Decantada e Decantada/Filtrada

\begin{tabular}{|c|c|c|c|c|}
\hline \multirow[t]{2}{*}{ Estaçōes } & \multicolumn{2}{|c|}{$\begin{array}{c}\text { Água } \\
\text { Bruta/Decantada }\end{array}$} & \multicolumn{2}{|c|}{$\begin{array}{c}\text { Água } \\
\text { Decantada/Filtrada }\end{array}$} \\
\hline & $\mathrm{R}$ & & $\mathrm{R}$ & \\
\hline ETA II & 0,557 & 0,310 & 0,130 & 0,017 \\
\hline ETA III & 0,571 & 0,326 & & \\
\hline ETA IV & 0,778 & 0,605 & & \\
\hline ETA V & 0,527 & 0,278 & 0,636 & 0,405 \\
\hline ETA VI & 0,561 & 0,314 & 0,475 & 0,226 \\
\hline ETA VII & 0,451 & 0,204 & 0,399 & 0,159 \\
\hline ETA VIII & 0,754 & 0,569 & 0,642 & 0,412 \\
\hline ETA IX.A & 0,714 & 0,510 & 0,652 & 0,425 \\
\hline ETA IX.B & 0,532 & 0,283 & 0,783 & 0,613 \\
\hline
\end{tabular}

ETA IX A e B - Antes e depois da reforma
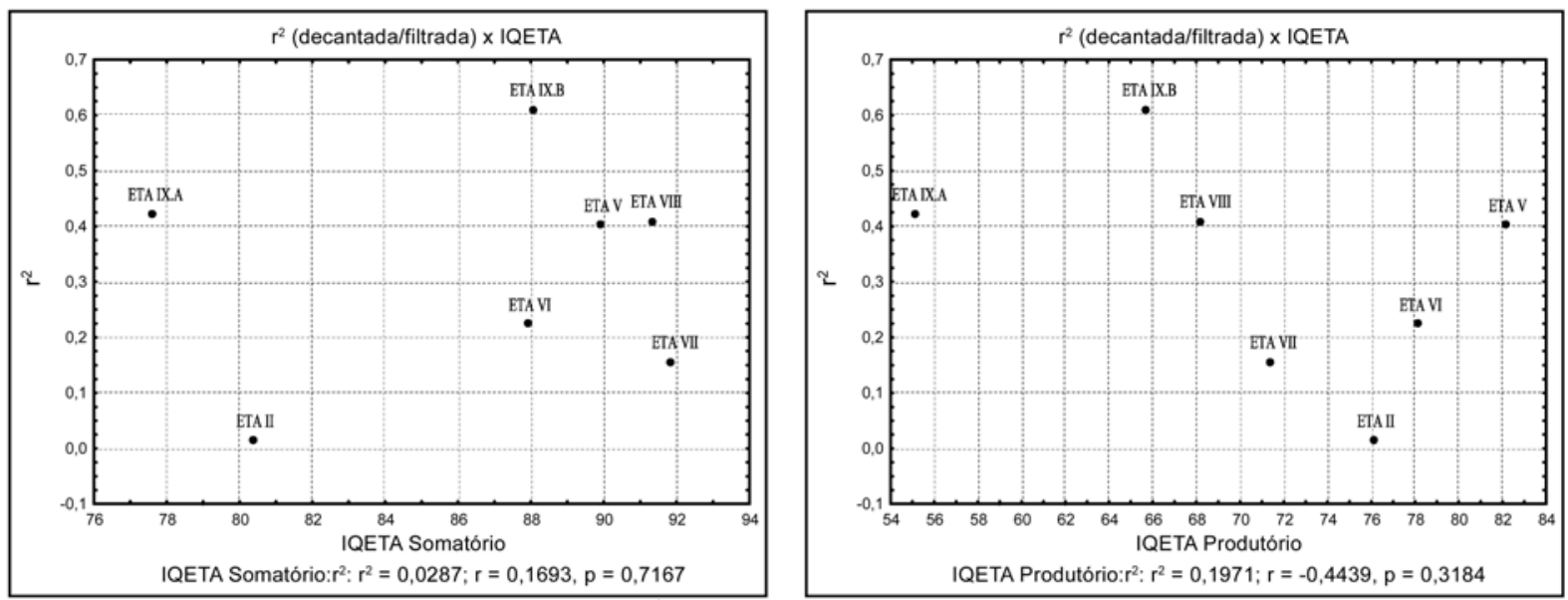

Figura 3 - Diagrama de dispersão $r^{2}$ x IQETA somatório e produtório (período chuvoso) 
sentaram os piores resultados para a decantação e filtração, respectivamente.

Será que as estações produzindo água filtrada de qualidade constante são as que possuem maior valor do IQETA? Para responder a esta questão foram plotados os gráficos da Figura 3, no eixo das abscissas IQETA somatório e produtório e nas ordenadas $\mathrm{r}^{2}$ entre a água decantada e a filtrada. Destes gráficos observa-se que a resposta afirmativa para a questão colocada acima foi totalmente rejeitada para o IQETA somatório. Já para o IQETA produtório, embora os resultados tenham sido baixos, foram significativamente melhores do que para o IQETA somatório.

A supremacia do IQETA produtório ao somatório pôde ser confirmada pela comparação deste com a correlação entre a água decantada e filtrada. Ou seja, estaçōes apresentando menores IQETA produtório apresentaram também menores correlações entre a água decantada e filtrada. A utilidade do IQETA pôde ser verificada também na comparação dos resultados da ETA IX.A e ETA IX.B, demonstrando-se sensível às melhorias da estação acompanhadas de melhoria da qualidade da água filtrada.

\section{CONCLUSÕES}

Verificou-se que as duas rodadas de questionários foram insuficientes para alcançar maior consenso entre os painelistas no valor dos pesos referentes aos parâmetros considerados mais relevantes. Para alguns parâmetros, inclusive, a dispersão aumentou na $2^{\mathrm{a}}$ rodada. Já a respeito da hierarquização dos parâmetros os questionários demonstraram haver um consenso a respeito dos mais relevantes. Sendo a primeira posição ocupada pela taxa de filtração, cuja importância coaduna-se com as tendências dos padróes de potabilidade nacionais e internacionais de privilegiar a redução dos valores permissíveis para a turbidez da água filtrada.

Apesar da limitação do tamanho da amostra de 10 estações de tratamento, as significativas correlações auferidas demonstraram que há uma tendência das estaçôes produzindo água filtrada de melhor qualidade, no que se refere a valores de turbidez, serem contempladas com maiores valores para o IQETA. Os valores de correlação apresentaram-se maiores para o IQETA produtório quando exigências mais restritivas para os valores $\mathrm{da}$ turdidez da água filtrada foram estabelecidas. No entanto, para as esta- ções com bom desempenho em todos os parâmetros os resultados obtidos com o IQETA somatório aproximam-se dos obtidos com o IQETA produtório.

Partindo-se do pressuposto que estações com bom desempenho devem ser capazes de produzir água filtrada com qualidade estável apesar das variações da água bruta, o IQETA produtório também sobressaiu-se ao somatório quando comparado com os valores de $\mathrm{r}^{2}$ entre os valores de turbidez para água decantada e os valores para a água filtrada, mostrando-se mais sensível e portanto mais capaz de hierarquizar as estaçóes atribuindo melhores resultados as com um desempenho realmente acurado.

Por fim, as correlações corroboraram as premissas nas quais os critérios de pontuação dos 19 parâmetros se calcaram e o próprio IQETA produtório como indicador para hierarquização das estações de tratamento de água, podendo vir a se tornar excelente ferramenta às administraçôes dos sistemas de abastecimento de água.

\section{RECOMENDAÇÕES}

Evidentemente que uma análise mais ampla haverá de contemplar além do IQETA e da qualidade da água tratada, um índice que afira as características da água bruta em termos de maior ou menor tratabilidade. Acredita-se que novos estudos podem aperfeiçoar o IQETA aumentando sua acurácia, partindo-se da exploração dos desacordos revelados nas duas rodadas. Também a realização de uma pesquisa de opiniāo acerca dos critérios de pontuação desenvolvidos poderá contribuir significativamente com o aperfeiçoamento destes. Por fim, a aplicação do IQETA a um número maior de estaçōes se faz necessária para a verificação da confirmação, ou não, dos resultados obtidos até o momento.

\section{AGRADECIMENTOS}

Os autores agradecem à Capes e ao CNPq, pela concessão da bolsa de mestrado e de produtividade em pesquisa ao primeiro e segundo autores, respectivamente. Novamente ao CNPq pelo financiamento da pesquisa no bojo do Edital Universal 2003 (processo 477481/2003-5) e aos administradores dos sistemas autônomos de água e esgoto de Minas Gerais e São Paulo pela cessão dos dados operacionais.

\section{REFERÊNCIAS BIBLIOGRAFICAS}

ASSOCIAÇÃO BRASILEIRA DE NORMAS TÉCNICAS - ABNT. NBR 12216. Projeto de estações de tratamento de água para abastecimento público. Rio de Janeiro, 1989.

BROWN, R. M. et al. A water quality index do we dare? Water \& Sewage Works, Chicago, v. 117, n 10 , p. 339-343, outubro.1970

CETESB. Manual de avaliação de desempenho de estaçôes de tratamento de água: manual técnico. São Paulo, 73p. 1980.

CONSONERY, P. J.; GREENFIELD, D N. \& LEE, J. J. - Pennsylvania's filtration evaluation program. JAWWA, v.89, n.8, p. 67-77, August 1997.

GUIDELINES FOR PHASE IV: Partnership for safe water. AWWA et al, 2003.

HELSEL, D. R. \& HIRSCH, R. M. Statistical methods in water resources. U.S. Geological survey. 503p. 2002

LINSTONE, H. A. (Ed) ; TUROFF, M. (Ed).The Delphi Method: techniques and applications. Addison-Wesley Publishing Company: Massachusetts, 620p. 1975.

MINISTÉRIO DA SAÚDE - MS. Portaria 518: Normas e padrão de potabilidade da água destinada ao consumo humano. Brasília, março.2004.

NIEMINSKI, E. C. \& ONGERTH, J. E. Removing Giardia and Cryptosporidium by conventional treatment and direct filtration. JAWWA, New York, v. 87, n. 9, p. 96-106, September1995 apud LeCHEVALIER, M. W. \& A, K. - Water Treatment and Pathogen Control, WHO, London, 112 p., 2004.

RENNER, R. C. et al. Composite Correction Program Optimizes Performance at Water Plants. JAWWA, v.85. , n. 6, p.67-74, June 1993.

TAYLOR, J. G. \& RYDER, S. D. Use of the Delphi method in resolving complex water resources issues. Journal of the Americam Water Resources Association, New York, v. 39, n.1, p. 183-189, February 2003.

TEIXEIRA, A. R. et al. A confiabilidade analitica dos valores de turbidez da água filtrada e seu efeito no cumprimento do padrão de potabilidade, Revista Engenharia Sanitária e Ambiental, vol. 9, n.1, p. 66-73, março 2004.

USEPA. Optimizing water treatment plant performance using composite correction program.Cincinnatti, Ohio: USEPA CERI. 168p.( EPA/625/3-87/013). 1998

Endereço para correspondência:
Marcelo Libânio
Departamento de Engenharia Hidráulica e Recursos Hídricos da UFMG
Av. Contorno, $842 / 8^{\circ}$ andar -
301 I 0-060 - Belo Horizonte -
MG - Brasil
Tel: (3I) 3238-1004
E-mail: mlibanio@ehr.ufmg.br 